- Journal Publications • Research Consultancy

\title{
AN ANALYSIS OF DIESEL WATER EMULSION IN THE
}

\section{DIRECT INJECTED DIESEL ENGINE}

\section{SHANMUGARAJ J, SIVASUBIRAMANIAM R, MUTHESWARAN R \& RAJA M}

Department of Mechanical Engineering, Einstein College of Engineering,

Sir. C. V. Raman Nagar, Tirunelveli, Tamil Nadu, India

\begin{abstract}
Diesel engines are mostly used in industries and transportation sectors while compared to petrol engines. The Diesel engine produces the emissions such as $\mathrm{NO}, \mathrm{HC}, \mathrm{PM}$ and $\mathrm{CO}$. It affects the environment and human health also. In the recent field water diesel emulsion is studied and replaced by the diesel. Water, diesel emulsion reduces the $\mathrm{NO}_{x}$ and due to the reduction in the temperature. Our aim is reduce the NO $\mathrm{w}_{x}$ without compensating the engine performance. Then performance and emission test were carried out by using the fuel in a single cylinder water cooled engine. Here the emulsion 1 \& emulsion 2 are compared with the diesel and it is found that the emulsion 2 is the best alternative to diesel.
\end{abstract}

KEYWORDS: Emulsion, Diesel Engine, Nitrogen Oxide, Hydro Carbon \& Carbon Monoxide

Received: Jan 9, 2019; Accepted: Feb 01, 2019; Published: Mar 07, 2019; Paper Id.: IJMPERDAPR201942

\section{INTRODUCTION}

The diesel engines release major emission which are harmful to the environment and also affects the human health. If the correct regulation for the emission control is followed, environmental pollution can be reduced drastically. Various techniques for emission control are introduction of biodiesel, catalytic convertor and water diesel emulsion fuel. In ordinary diesel engine there is a formation of $\mathrm{NO}_{\mathrm{x}} \& \mathrm{HC}$ which are formed by entirely different process [1]. So the reduction of these compounds simultaneously is very difficult as these are done using an entirely different process. So the alternative for this emission control is the usage of emulsified diesel. It reduces the emission around 51\%. The most economical method among these is the water diesel emulsion fuel, which can be used without any modification in the engine [2]. The various advantages associated with this technique are efficient combustion, better fuel economy, controlling the emission of $\mathrm{NO}_{\mathrm{x}}[3]$. Water diesel emulsion also compensate the SFC, BTE. Atomisation is a major factor which affects the emission. As the ambient condition is varied it affect the atomization.

One of the major pollution is carbon pollution, which is mainly formed due to incomplete combustion of carbon containing compounds. As the efficiency of the combustion process is increased, the carbon emission is reduced. $\mathrm{NO}_{\mathrm{x}}$ consist of nitrogen oxide, $\mathrm{NO}_{2}$. Which accounts for the $50 \%$ of the total emission. $\mathrm{NO}_{\mathrm{x}}$ indirectly causes ozone layer depletion. So it is an indirect greenhouse gas. Particulate matters are the particles which arise from combustion sources. Secondary particles are mainly sulphate $\&$ nitrate formed in the atmosphere and coarse particles. These are smaller than 10 microns. Ultrafine particles are smaller than 2.5 microns. Volatile organic components are the compounds which react with $\mathrm{NO}_{\mathrm{x}}$ to form ozone. It is an indirect greenhouse gas. High 
concentration of VOC occurs at downwind of the source emission, mainly occur during the summer season.

\section{MATERIAL AND METHOD}

\subsection{Emulsion Preparation}

In the present research work, the ultrasonic probe sonicator was used in the emulsification process for preparing a capacity of $1000 \mathrm{ml}$ solution, a frequency of $1500 \mathrm{~Hz}$ is used. It has 3 components, Controller unit, Chamber with adjustable stand, Ultrasonic probe. The water and diesel are immiscible liquids in order to mix it we use surfactants. Commonly used surfactants are span 20 with a HLB value of 4.3 and tween 80 with a HLB 15 . The quantity of surfactants used in this emulsion preparation was $1 \& 2 \%$ by volume [1]. Here using only $5 \%$ of water with various percentage of diesel. 1 litre diesel is mixed with the surfactants and this mixture is placed inside the ultrasonic probe sonicator for further operation. The solution preparation takes 90 to $100 \mathrm{~min}$ for a half litre.

\subsection{Emulsion Stability}

Table 1: Range of Emulsion

\begin{tabular}{|l|c|c|l|}
\hline \multicolumn{1}{|c|}{ Fuel } & Diesel (\%) & Water (\%) & \multicolumn{1}{c|}{ Surfactant (\%) } \\
\hline Diesel & 100 & - & - \\
\hline Emulsion 1 & 94 & 5 & 0.5 span 20 \& 0.5 tween 80 \\
\hline Emulsion 2 & 93 & 5 & 1 span20 \& 1 tween 80 \\
\hline
\end{tabular}

By keeping the water diesel emulsion in a glass container, in a closed room, (EM 1 \& 2) is investigated and it is found that the water in diesel emulsion is stable for 15 days and no separation occurred.

\subsection{Properties of Fuel}

Properties of diesel and water diesel emulsion were calculated by using various types of equipment. Here the density was calculated by volume mass basis.

Table 2: Properties of Fuel

\begin{tabular}{|l|c|c|}
\hline & Diesel & Emulsion \\
\hline Density (kg / m & 832 & 836 \\
\hline Calorific value $(\mathrm{MJ} / \mathrm{kg})$ & 44.2 & 42.3 \\
\hline Flash point & 58 & 60 \\
\hline Fire point & 63 & 68 \\
\hline
\end{tabular}

Viscosity is measured using the Redwood viscometer, Calorific value is measured using the Bomb calorimeter, and the Flash and fire point is measured using the Pensky martens apparatus.

\subsection{Engine Setup}

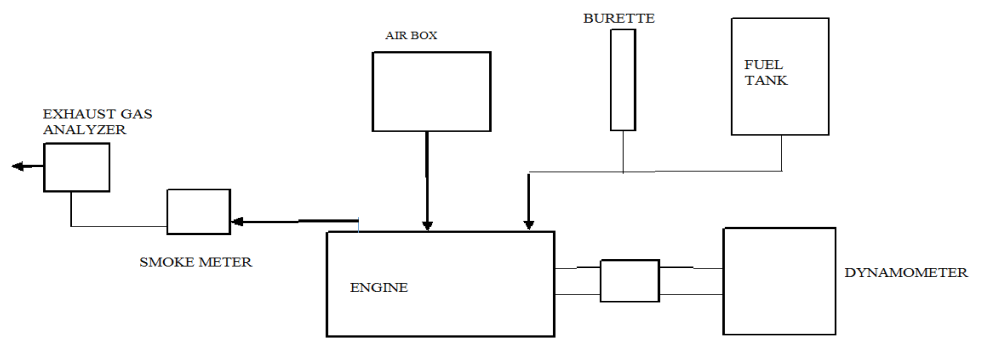

Figure 1: Engine Setup 
This is the schematic diagram of engine setup. The engine used here is a four stroke, single cylinder water cooled engine. The engine is connected to the dynamometer. The dynamometer is used in order to provide varying loads. The fuel tank is connected to the engine in order to provide diesel. This setup is connected to a computer interface to get automated data. It is connected with AVL DI gas analyser. To analyse the emission like $\mathrm{CO}, \mathrm{CO}_{2}, \mathrm{NO}_{\mathrm{x}}$. The AVL smoke meter is used to measure the smoke.

\section{RESULTS AND DISCUSSIONS}

The investigation was carried out on diesel engine and tested with various emulsion fuels

\subsection{Specific Fuel Consumption}

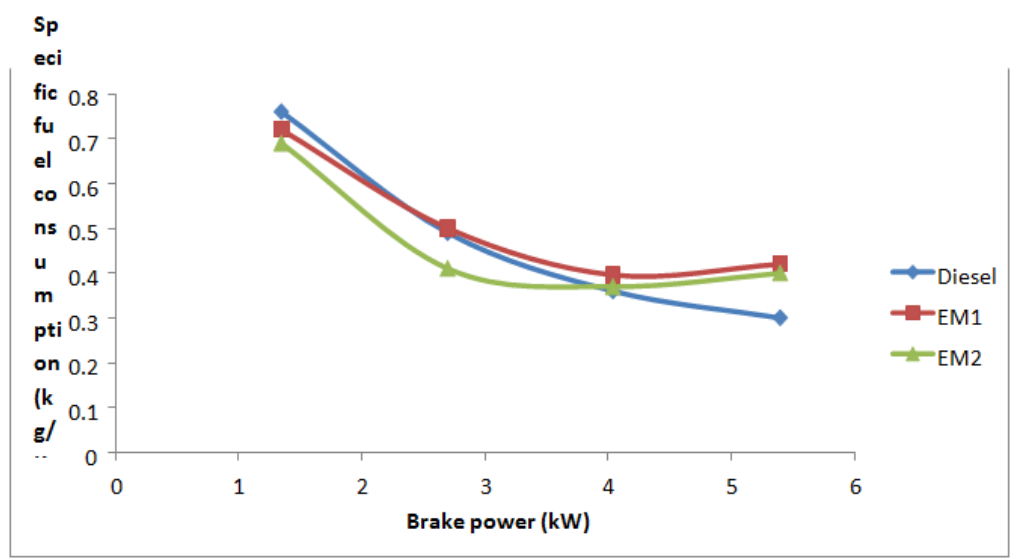

Figure 2: Brake Power vs Specific Fuel Consumption

The mileage of the vehicle is the major aspect that the customer looks for, but it mainly depends upon SFC. Specific fuel consumption of an engine is defined as the amount of fuel used in $\mathrm{kg}$ per brake power per sec.

$$
\mathrm{SFC}=\frac{\text { mass of fuel }(\mathrm{kg})}{b p(k w) * \text { time }(\mathrm{hr})}
$$

From the graph, its come to know that the fuel consumption is increased during the high load condition while compared to diesel and emulsion 1. Combustion efficiency of the engine is increased by increasing the use of water add by keeping the temperature in the working range.

\subsection{Brake Thermal Efficiency}

The brake power and brake thermal efficiency was decreased using water diesel emulsion when compared to ordinary diesel.

$$
\mathrm{BTE}=\frac{b p}{\text { calorific value } * \text { fuel consumption per sec }}
$$




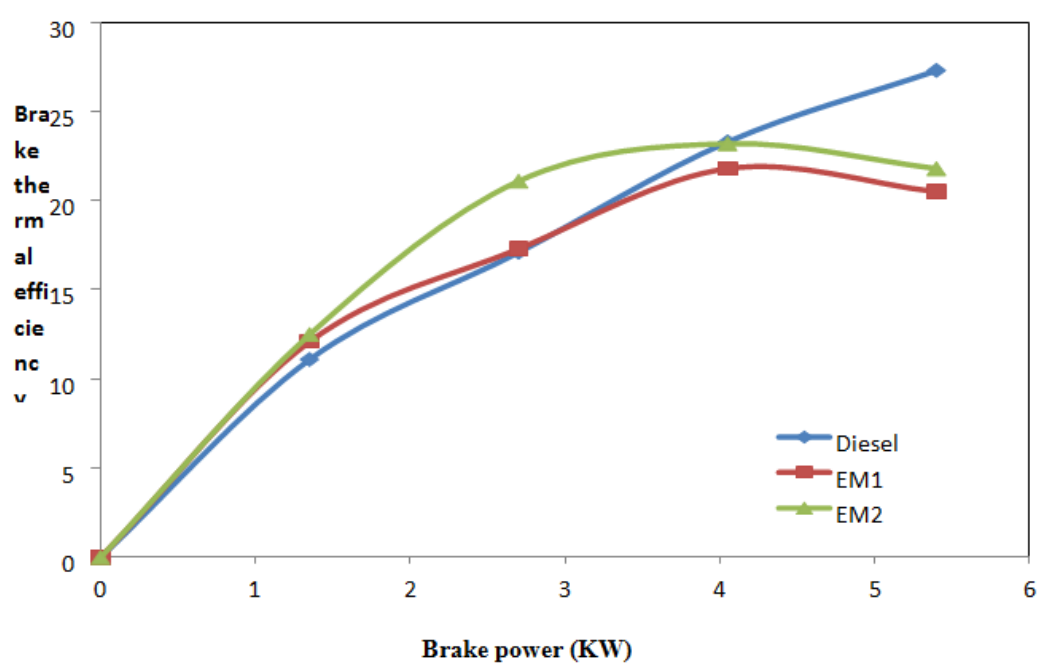

Figure 3: Brake Power vs Brake Thermal Efficiency

From the graph, it is visible, that at the starting stage brake thermal efficiency of diesel, emulsion $1 \& 2$ are same. At the off load condition, efficiency of diesel and emulsion 1 is less than the emulsion 2 at a certain level. Which reached a full load condition, brake thermal efficiency of emulsion 2 is decreased while compared with pure diesel.

\section{EMISSION ANALYSIS}

\subsection{Nitrogen Oxide $\left(\mathrm{No}_{\mathbf{x}}\right)$}

The $\mathrm{NO}_{\mathrm{x}}$ emission was significantly reduced by using water diesel emulsion fuels (EM 1 \& EM 2) compared to the diesel. The nitrogen oxide emission is reduced due to the lower combustion temperature of water diesel emulsion fuel [4]. The $\mathrm{NO}_{\mathrm{x}}$ emission was measured using the AVL DI gas analyser. Water diesel emulsion 2 is the optimal fuel for reducing $\mathrm{NO}_{\mathrm{x}}$ emission and shows average reduction of $51 \%$ of load in every condition.

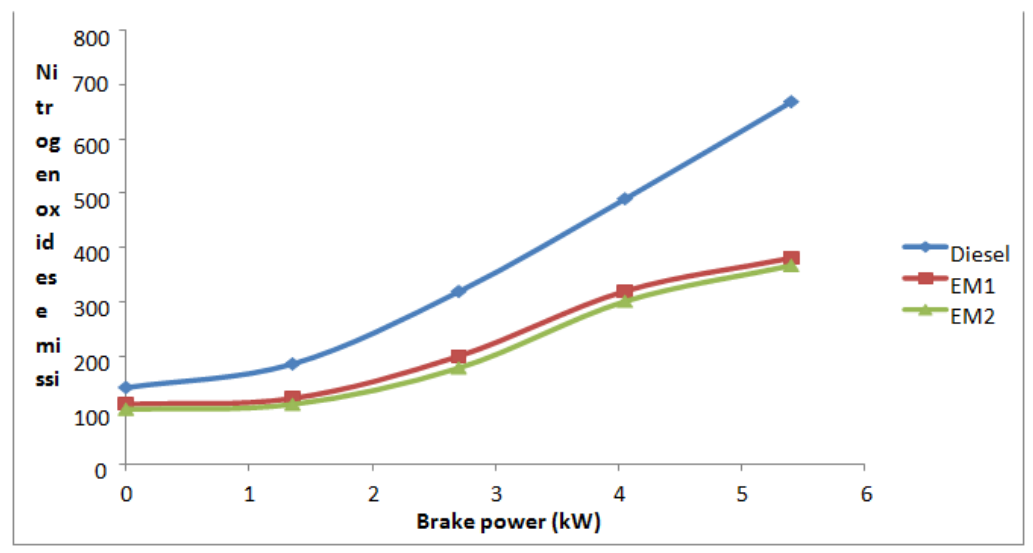

Figure 4: Brake Power vs Nitrogen Oxide

\subsection{Carbon Monoxide}

Carbon monoxide is emitted due to the incomplete combustion of carbon and oxygen inside the cylinder [5]. When the volume of water in emulsion increases, the emission of carbon monoxide is also increased, because of the presence of water inside the cylinder is slowing down the combustion of carbon, which results in incomplete combustion. 


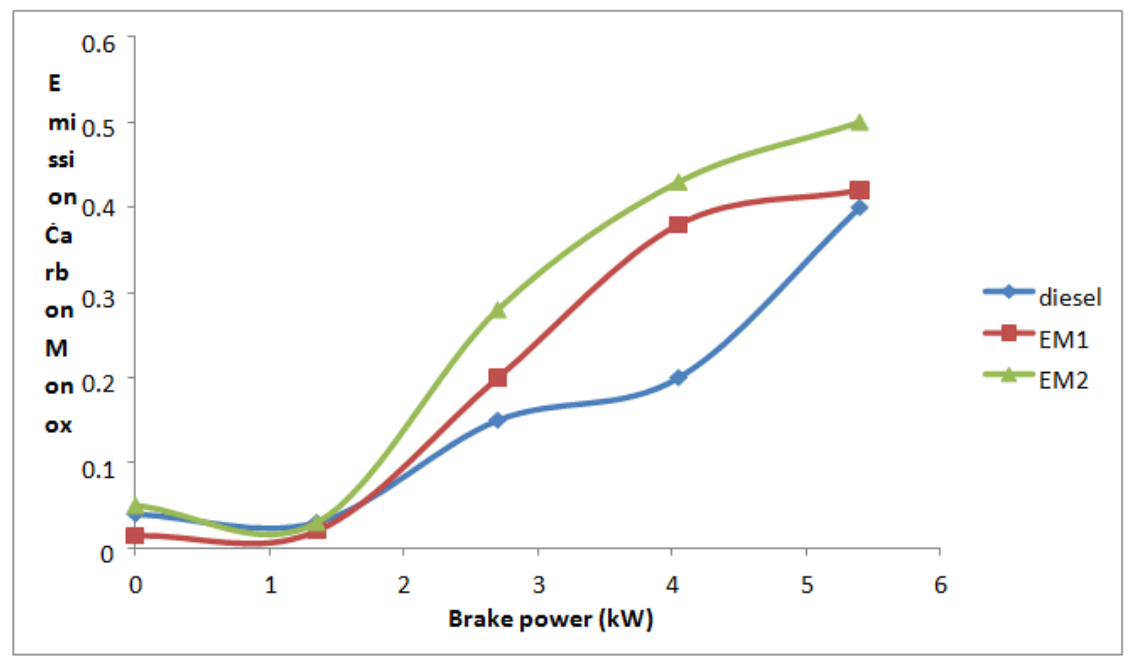

Figure 5: Brake Power vs Carbon Monoxide

\subsection{Hydrocarbon Emission}

The emission from the CI engine contains around 100ppm of HC. It formed due to breaking up of larger molecules during the combustion process. So, the treatment of these type of molecules are necessary [6]. At low load condition diesel gives more $\mathrm{HC}$ emission than emulsion. But at high load condition emission of $\mathrm{HC}$ is higher in emulsion than diesel.

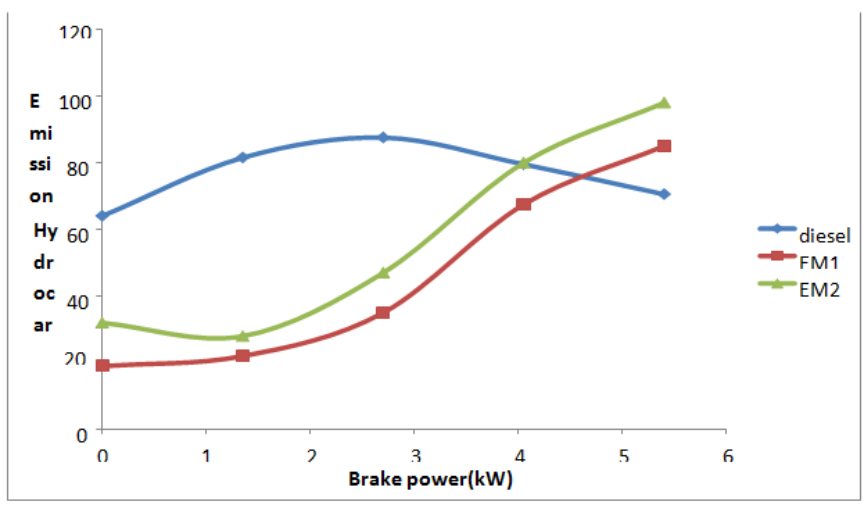

Figure 6: Brake Power vs Hydrocarbon

\subsection{Carbon Dioxide}

Carbon monoxide is formed due to incomplete combustion of carbon particle and carbon monoxide inside the cylinder. As the load increases $\mathrm{CO}_{2}$ emission also increases when diesel is used as the fuel also in the emulsion two $\mathrm{CO}_{2}$ emission increases some variation. 


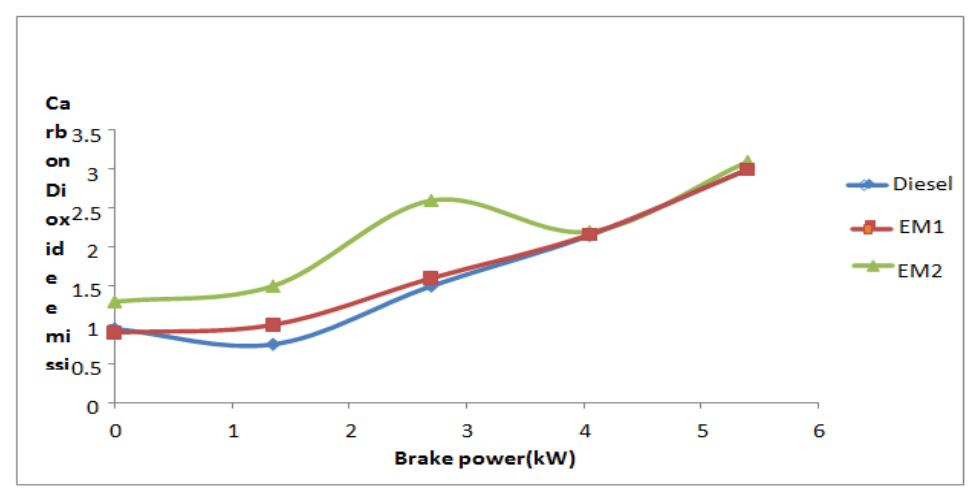

Figure 7: Brake Power vs Carbon Dioxide

\section{CONCLUSIONS}

The major conclusion is drawn from the investigation follows,

- Water diesel emulsion fuel significantly reduces the $\mathrm{NO}_{\mathrm{x}}$ emission

- Emulsion 2 is best alternative solution than compared with diesel and emulsion 1.

- At lower loads the hydrocarbon emissions are lesser for emulsion as compared to diesel.

- Carbon monoxide and carbon dioxide emissions increase with increase in water percentage in the fuel. This is due to the fact that most of the hydrocarbons are burnt at lower loads.

\section{REFERENCES}

1. Senthur, N. S., \& Ravikumar, T. S., (2018). Performance and emission characteristics analysis of thermal barrier coated LHR engine fuelled with Eucalyptus - water emulsion. International journal of ambient energy.1-6. DOI: 10.1080 / 01430750.2018 .1501747 .

2. Lin, C. Y., \& Chen, L. W., (2018). Comparison of fuel properties and emission characteristic of two and three phase emulsion prepared by ultrasonically vibrating and mechanically homogenizing emulsification methods, 10, 2154-2161.

3. Rao, N. D. P., Krishna, M. M., Prasad, B. A., \& MURTHY, P. The effect of thermal barrier coating on exhaust emissions and combustion characteristics of diesel engine with rice brawn oil based biodiesel. International Journal of Research in Engineering and Technology, ISSN (E), 2321-8843.

4. Senthur, N. S., \& Ravikumar, T. S., (2018). Comparative evaluation of performance and emission characteristic of jatropha, pongamia, mahua and eucalyptus oil based bio diesel in diesel engine. International journal of mechanical and production engineering research and development, 4, 813 - 822 .

5. Madhu, G. M., Kumar, S. M., Raj, M. A. L., (2007). Studies on separation of liquid-liquid dispersion. Diesel-water system in batch settler. Journal of dispersion science and technology, 28, 1123-1131.

6. Fan, X. (2008). A new emulsifier behaviour of the preparation for micro emulsified diesel oil. Journal of petroleum science and technology, 26, 2125-2136.

7. Hymavathi, D., Prabhakar, G., \& Sarath, B. B. (2014). Biodiesel production from vegetable oils: an optimization process. Int J Chem Petrochem Technol, 4(2), 21-30.

8. Senthur, N. S., Ravikumar, T. S., \& Cijil John, B., (2014). Eucalyptus biodiesel: an environmental friendly fuel for compression ignition engine. Americal journal of engineering research, 3, $144-149$. 